\title{
Aerobic bacteria associated with chronic suppurative otitis media in Angola
}

Fabian Uddén', Matuba Filipe², Åke Reimer ${ }^{1,3}$, Maria Paul', Erika Matuschek ${ }^{4}$, John Thegerström', Sven Hammerschmidt ${ }^{5}$, Tuula Pelkonen ${ }^{6}$ and Kristian Riesbeck ${ }^{1 *}$ (i)

\begin{abstract}
Background: Chronic suppurative otitis media (CSOM) is an important cause of hearing loss in children and constitutes a serious health problem globally with a strong association to resource-limited living conditions. Topical antibiotics combined with aural toilet is the first-hand treatment for CSOM but antimicrobial resistance and limited availability to antibiotics are obstacles in some areas. The goal of this study was to define aerobic pathogens associated with CSOM in Angola with the overall aim to provide a background for local treatment recommendations.
\end{abstract}

Methods: Samples from ear discharge and the nasopharynx were collected and cultured from 152 patients with ear discharge and perforation of the tympanic membrane. Identification of bacterial species was performed with matrix-assisted laser desorption/ionization-time of flight mass spectrometry and pneumococci were serotyped using multiplex polymerase chain reactions. Antimicrobial susceptibility testing was done according to EUCAST.

Results: One hundred eighty-four samples from ear discharge and 151 nasopharyngeal swabs were collected and yielded 534 and 289 individual isolates, respectively. In all patients, correspondence rate of isolates from 2 ears in patients with bilateral disease was $27.3 \%$ and $9.3 \%$ comparing isolates from the nasopharynx and ear discharge, respectively. Proteus spp. (14.7\%), Pseudomonas aeruginosa (13.2\%) and Enterococcus spp. (8.8\%) were dominating pathogens isolated from ear discharge. A large part of the remaining species belonged to Enterobacteriaceae (23.5\%). Pneumococci and Staphylococcus aureus were detected in approximately 10\% of nasopharyngeal samples. Resistance rates to quinolones exceeded $10 \%$ among Enterobacteriaceae and was $30.8 \%$ in S. aureus, whereas $6.3 \%$ of $P$. aeruginosa were resistant.

Conclusions: The infection of the middle ear in CSOM is highly polymicrobial, and isolates found in nasopharynx do not correspond well with those found in ear discharge. Pathogens associated with CSOM in Angola are dominated by gram-negatives including Enterobacteriaceae and P. aeruginosa, while gram-positive enterococci also are common. Based on the results of antimicrobial susceptibility testing topical quinolones would be the preferred antibiotic therapy of CSOM in Angola. Topical antiseptics such as aluminium acetate, acetic acid or boric acid, however, may be more feasible options due to a possibly emerging antimicrobial resistance.

Keywords: Chronic suppurative otitis media, Enterobacteria, Infection, Otitis media, Proteus, Pseudomonas aeruginosa

\footnotetext{
* Correspondence: kristian.riesbeck@med.lu.se

${ }^{1}$ Clinical Microbiology, Department of Translational Medicine, Faculty of

Medicine, Lund University, Malmö, Sweden

Full list of author information is available at the end of the article
}

(c) The Author(s). 2018 Open Access This article is distributed under the terms of the Creative Commons Attribution 4.0 International License (http://creativecommons.org/licenses/by/4.0/), which permits unrestricted use, distribution, and reproduction in any medium, provided you give appropriate credit to the original author(s) and the source, provide a link to the Creative Commons license, and indicate if changes were made. The Creative Commons Public Domain Dedication waiver (http://creativecommons.org/publicdomain/zero/1.0/) applies to the data made available in this article, unless otherwise stated. 


\section{Multilingual abstracts}

Please see Additional file 1 for translation of the abstract into the six official working languages of the United Nations.

\section{Background}

Chronic suppurative otitis media (CSOM) is a prolonged and often recurring bacterial infection of the middle ear defined by perforation of the tympanic membrane and otorrhoea lasting more than 2 weeks according to the World Health Organization (WHO), although a commonly used clinical definition is 6 weeks. The infection usually develops in early childhood, with a peak around 2 years of age, but can persist until adulthood $[1,2]$. WHO estimates that 65 to 330 million people suffer from CSOM worldwide. The greatest burden of disease is found in low-income countries in Sub-Saharan Africa and Oceania, where incidence rates over $0.7 \%$ have been reported, with higher numbers among children under 5 years of age [1, 3]. Furthermore, certain ethnical groups are particularly affected, including the Inuit of Greenland, Native Americans and Aboriginal Australians [2]. Risk factors associated with CSOM include frequent episodes of acute otitis media (AOM), other respiratory tract infections, and traumatic tympanic rupture as well as factors correlating with resource-limited living conditions such as overcrowding, poor nutrition and hygiene, and chronic infectious diseases. Even if the pathogenesis is multifactorial, the clinical onset is frequently an episode of AOM complicated by tympanic membrane perforation and a subsequent superinfection of the middle ear with bacteria entering through the outer ear channel. Additionally, perforated tympanic membrane causes Eustachian tube dysfunction, allowing for pathogens to ascend to the middle ear through reflux of nasopharyngeal secretions [2, 4]. Formation of biofilm has been implicated to sustain the infection and reduce the efficacy of antibiotic treatment [5]. CSOM is an important cause of conductive as well as sensorineural hearing loss in children, which may be the result in more than $50 \%$ of patients. Moreover, facial nerve paralysis, sinus thrombosis, labyrinthitis, meningitis and brain abscesses are other rare complications. The WHO estimates that up to 28000 yearly deaths can be attributed to CSOM on a global basis [1].

Microbiological findings in CSOM vary between studies. However, the bacterial spectrum most often identified in the CSOM-affected middle ear is dominated by Pseudomonas aeruginosa, Staphylococcus aureus and Enterobacteriaceae such as Proteus spp. and Klebsiella pneumoniae $[1,2,4]$. Anaerobic bacteria are commonly detected in studies of CSOM applying suitable anaerobic methods for isolation. Infections are often polymicrobial and a synergistic relationship between aerobes and anaerobes has been suggested [2, 6]. Mycobacterium tuberculosis is a rare cause of chronic infection of the middle ear, but tuberculous otomastoiditis has to be considered in a patient presenting with chronic ear discharge [7].

Being an important cause of pediatric hearing loss in developing countries that is potentially preventable, studies facilitating efficient care of CSOM are highly desirable. As the pathogenesis and varying microbiology of CSOM are not fully understood, it is of importance to investigate the prevalence of various pathogens in different areas [2]. Knowledge on the local incidence as well as spectrum of bacteria present and their antimicrobial susceptibility patterns is imperative for effective empirical treatment as well as contributing to the general understanding of the disease [6].

Luanda, the capital of Angola, has a population of approximately 6 million in 2014, and is one of the fastest growing cities in Africa, where a large part of the population lives in conditions lacking sanitation, fresh drinking water and with a high mortality rate among children under 5 years of age $[8,9]$. Studies during 1981-1982 showed a CSOM prevalence of $2-4 \%$ in school children in Luanda [10]. Moreover, studies from 2011 reported CSOM in $4 \%$ of healthy children in Luanda and higher numbers in those with comorbidities such as HIV and tuberculosis [11, 12]. Studies on antimicrobial susceptibility of pathogens involved in CSOM from Angola are scarce, and generally do not regard the antibiotics commonly used to treat this particular infection. A high incidence of methicillin resistant S. aureus (MRSA) and carbapenemase-producing Enterobacteriaceae has, however, been reported [13, 14]. In the current study, we present microbiological findings from middle ear discharge and the nasopharynx in patients with CSOM in Luanda and three other provinces in Angola with the aim to provide a background for recommendations on the treatment of the disease in the public health care system.

\section{Methods \\ Study design}

The present study is a part of a project at the Ear, nose and throat (ENT)-department at Hospital Josina Machel (HJM) in Luanda to improve otitis media care and prevent hearing loss. AOM and CSOM are among the most frequent reasons for attending this clinic, which until 2016 was the only public ENT-clinic in Luanda. Clinical samples and patient information were collected from patients of all ages with CSOM at the outpatient section of the HJM ENT-clinic and at health care centers in three other Angolan provinces (Lunda Sul, Namibe, Zaire) from January to December 2016. CSOM was defined as perforation of the tympanic membrane confirmed by otoscopy and purulent ear discharge lasting more than 14 days. 


\section{Sampling and culture conditions}

Sampling for microbiological cultures was conducted by experienced clinicians using standard techniques. After cleaning the auditory channel with $70 \%$ ethanol, ear discharge samples were collected with a swab. For nasopharyngeal sampling, a swab was introduced into nasopharynx through the nostril crossing the choana until it touched the wall of the nasopharynx. Samples from both loci were collected in skim milk-tryptoneglucose-glycerol (STGG) medium and stored at $-70{ }^{\circ} \mathrm{C}$ at the Public Health Laboratory (Luanda) prior to transport to the Riesbeck laboratory (Malmö, Sweden). Clinical specimens were cultured on hematin agar, Columbia CNA agar (Oxoid, Hampshire, UK), and UriSelect agar supplemented with vancomycin (Bio-Rad, Hercules, CA) and incubated at $35.5{ }^{\circ} \mathrm{C}$ in $5 \% \mathrm{CO}_{2}$ (hematin and Columbia CNA agar) or at aerobic conditions (UriSelect) for $16-18 \mathrm{~h}$.

\section{Species identification and serotyping of pneumococci}

Bacterial species identification was done by Matrixassisted laser desorption/ionization - time of flight mass spectrometry (MALDI-TOF MS) [15]. Briefly, bacteria from a single colony of each isolate were applied to a MALDI target plate (Bruker Daltonics, Bremen, Germany) in duplicates and were overlaid with $1 \mu \mathrm{l}$ HCCA matrix (Bruker Daltonics) and let dry completely. Mass spectra were then acquired with a microflex MALDI-TOF mass spectrometer with flexControl software (Bruker Daltonics, Bremen, Germany) using default settings (mass range of spectra, m/z 2000 to 20000 in linear positive-ionization mode), and species were identified using the MALDI Biotyper 4.1 software with Bruker taxonomy library $(N=6903)$ (Bruker Daltonic). Streptococcus pneumoniae were serotyped using multiplex polymerase chain reaction (mPCR) [16]. Briefly, DNA was prepared from each pneumococcal isolate by boiling bacteria in Tris-EDTA-buffer and thereafter analysed in 6 sequential mPCRs containing, in total, 32 primer pairs identifying genes specific to different serotypes or groups of serotypes. A primer pair identifying the pneumococcus cpsA gene was included in all reactions as internal positive control indicating successful reaction. Primer sequences and the distribution of primer pairs to the different reactions, as well as PCR cycling conditions are presented in Additional file 2. If a pneumococcal serotype could not be identified by MPCR or further serotyping was needed to distinguish individual serotypes the Pneumotest Latex Kit and Neufeldt Antisera (Statens Seruminstitut, Copenhagen, Denmark), both based on the Quellung-reaction of capsular swelling, were used according to the manufacturer's instructions.

\section{Antimicrobial susceptibility testing}

Antimicrobial susceptibility testing was performed with disc diffusion according to European Committee on Antimicrobial Susceptibility Testing for all antibiotics except colistin, for which broth microdilution was performed on MICRONAUT-S plates (Merlin Diagnostika, Bornheim, Germany) according to the manufacturer's instructions. Susceptibility testing was done on the species that are generally regarded as being relevant for the pathogenesis of CSOM or AOM and the results were interpreted according to Breakpoint Tables of the European Committee on Antimicrobial Susceptibility Testing [17]. A number of isolates of the relevant species were not available for susceptibility testing. These isolates were, however, missing at random.

\section{Statistical analysis}

Descriptive statistics are used to present demographics, species distribution and microbial susceptibility. All data were computerized and analysed using Microsoft Excel version 15.37 (Microsoft, Redmond, WA) and are presented as absolute numbers and percentages.

\section{Results \\ CSOM is mainly found in children less than 12 years of age}

In total, 152 patients with tympanic membrane perforation and ear discharge lasting more than 14 days, attending the ENT-clinic or health care centers, were included in the study. A majority were from Luanda (77\%; $N=111)$, whereas $17 \%(N=24), 5 \%(N=7)$ and $1 \%(N=2)$ of patients were from Lunda Sul, Zaire and Namibe, respectively (Fig. 1). For 8 individuals, information about enrolment site was missing. Patient age ranged from 0 to 77 years and the median age was 12.6 years. Sixty-two percent $(N=91)$ of the patients were male while $38 \%(N=56)$ were female. A list of all patients, including demographical data and a listing of all microbiological findings is supplied in Additional file 3.

\section{Co-colonization by several different species is common in the CSOM-affected middle ear}

Samples from ear discharge from one or both ears $(N=184)$ and nasopharyngeal swabs $(N=151)$ were collected. A total of 823 microbes were identified, 534 in samples from ear discharge and 289 in nasopharyngeal samples. The mean number of isolates per sample was slightly higher in ear discharge samples than in nasopharyngeal samples (2.9 vs. 2.4, respectively). Only 16 ear samples yielded a single isolate as compared to 55 nasopharyngeal swabs. Of 187 isolates recovered from the middle ears in patients with bilateral disease, $52(27.3 \%)$ were isolates of the same species present in both ears of the same individual. On the other hand, 9.3\% $(N=27)$ of the nasopharyngeal isolates corresponded to an 


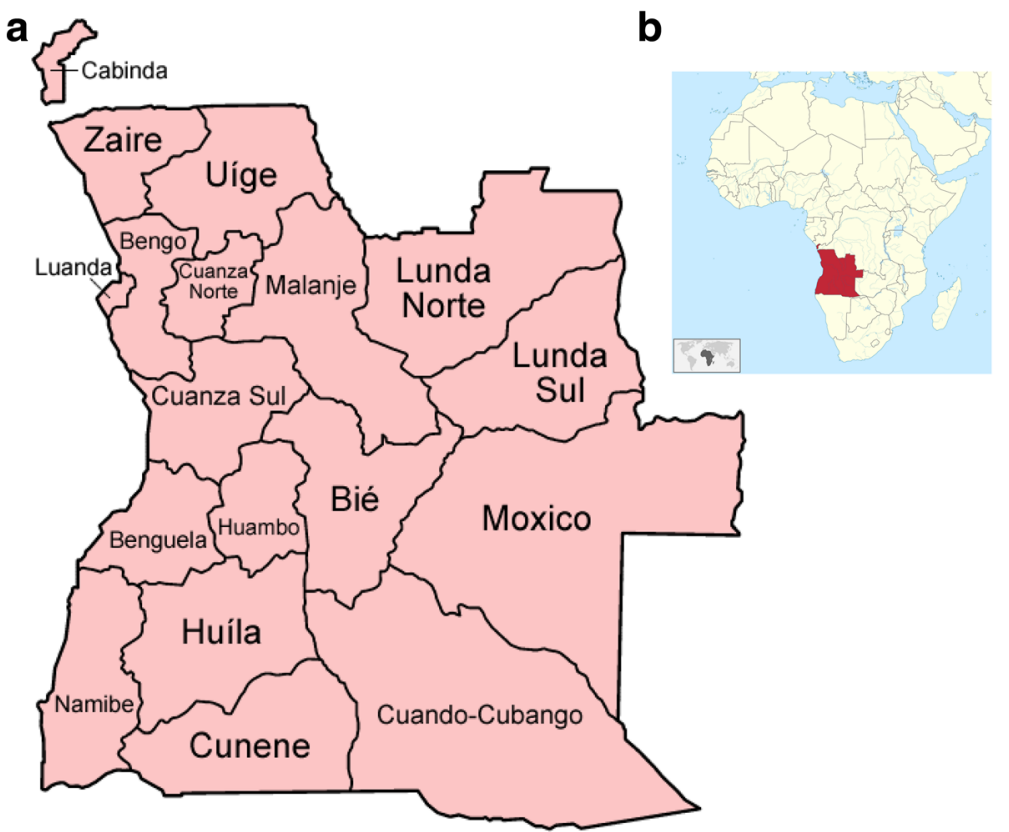

Fig. 1 a Map of Angola and its provinces [39] (by Golbez used under CC BY 2.5, https://creativecommons.org/licenses/by/2.5/). b Location map of Angola in Africa [40] (by TUBS used under CC BY-SA 3.0, https://creativecommons.org/licenses/by-sa/3.0/)

isolate simultaneously present in ear discharge from the same patient. The number of samples and isolates with regard to age group are described in Table 1.

\section{Proteus spp., Pseudomonas aeruginosa and enterococci dominate in CSOM}

A summary of the microbiological findings is presented in Table 2. In ear discharge samples, 87 different species were identified; Proteus spp. (14.7\%), P. aeruginosa (13.2\%) and Enterococcus spp. (8.8\%) were, however, dominating. Other Enterobacteriaceae constituted a large group, representing $23.5 \%$ of isolates, in which
Providencia spp., Morganella morganii, Citrobacter spp. and Klebsiella spp. were the most prevalent bacteria. In contrast, Pseudomonas spp. other than $P$. aeruginosa (16.0\%), pneumococci $(10.9 \%)$ and S. aureus $(8.2 \%)$ were dominating in nasopharyngeal samples, beside the abundant occurence of coagulase-negative staphylococci (CoNS) (30.7\%). Of 34 pneumococcal isolates, 35.3\% $(N=12)$ were identified as serotypes included in the 13valent pneumococcal conjugate vaccine (PCV13). Serotype 19F $(N=4)$ was the most common serotype followed by serotype $6 \mathrm{~A}(N=3)$ and non-PCV13 serotype $17 \mathrm{~F}(N=3)$ (Table 3$)$.

Table 1 Demographics of the study population and numbers of samples collected and pathogens isolated with regard to age group

\begin{tabular}{|c|c|c|c|c|c|c|c|c|c|c|}
\hline \multirow{2}{*}{$\begin{array}{l}\text { Age group } \\
\text { (years) }\end{array}$} & \multirow[t]{2}{*}{$N(\%)$} & \multirow{2}{*}{$\begin{array}{l}\text { Gender } \\
\text { (male/ } \\
\text { female) }\end{array}$} & \multicolumn{2}{|c|}{ Ear discharge samples } & \multicolumn{2}{|c|}{ Nasopharyngeal samples } & \multicolumn{2}{|c|}{ Total } & \multicolumn{2}{|c|}{ Corresponding isolates ${ }^{3}$} \\
\hline & & & $N$ & Isolates $^{2}$ & $N$ & Isolates $^{2}$ & $N$ & Isolates $^{2}$ & Ear/Ear & Ear/Nph \\
\hline$<5$ & $34(22)$ & $20 / 14$ & 44 & $124(2.8[0-5])$ & 34 & $104(3.1[1-6])$ & 78 & 194 (2.5 [0-6]) & $10(18.2)$ & $7(10)$ \\
\hline $5-9$ & $23(15)$ & $15 / 8$ & 26 & $81(3.1[0-6])$ & 23 & $52(2.3[0-3])$ & 49 & $117(2.4[0-6])$ & $7(36.8)$ & $3(8.3)$ \\
\hline $10-14$ & $24(16)$ & $16 / 8$ & 31 & $97(3.1[1-7])$ & 24 & $51(2.1[0-5])$ & 55 & $144(2.6[0-7])$ & $15(33.3)$ & $6(12.8)$ \\
\hline$\geq 15$ & $55(36)$ & $33 / 22$ & 66 & $184(2.8[1-6])$ & 54 & $109(2.0[0-4])$ & 120 & $286(2.4[0-6])$ & $18(29.5)$ & $11(10.8)$ \\
\hline No age data & $16(11)$ & $7 / 4$ & 17 & $48(2.8[1-4])$ & 16 & $45(2.8[1-4])$ & 33 & $96(2.9[1-4])$ & $2(28.6)$ & 0 \\
\hline Total & 152 & $91 / 56$ & $184^{4}$ & $534(2.9[0-7])$ & $151^{5}$ & $361(2.4[0-6])$ & 335 & $823(2.5[0-7])$ & $52(27.3)$ & $27(9.3)$ \\
\hline
\end{tabular}

No data about age or gender was available for 16 and 5 patients, respectively

${ }^{1}$ Gender data was missing for 5 patients

${ }^{2}$ Presented as $N$ (mean number of isolates per sample [range])

${ }^{3}$ Number of species present in two ear discharge samples, or in samples from ear discharge and the nasopharynx, from the same patient. Presented as $\mathrm{N}$ (\%)

${ }^{4}$ Bilateral samples were collected from 32 patients

${ }^{5}$ No nasopharyngeal sample was collected from 1 patient 
Table 2 Microbiological findings in samples from ear discharge and the nasopharynx

\begin{tabular}{|c|c|c|c|}
\hline \multicolumn{2}{|c|}{ Isolates from ear discharge $(N=534)$} & \multicolumn{2}{|c|}{ Isolates from nasopharynx $(N=289)$} \\
\hline Pathogen & $N(\%)$ & Pathogen & $N(\%)$ \\
\hline Proteus spp. & $79(14.7)$ & CoNS & $90(30.7)$ \\
\hline Pseudomonas aeruginosa & $71(13.2)$ & Pseudomonas spp. & $47(16.0)$ \\
\hline Enterococcus spp. & $47(8.8)$ & Streptococcus pneumoniae & $32(10.9)$ \\
\hline Providencia spp. & $42(7.8)$ & Staphylococcus aureus & $24(8.2)$ \\
\hline CoNS & $39(7.3)$ & Proteus spp. & $12(4.1)$ \\
\hline Corynebacterium spp. & $31(5.8)$ & Moraxella catarrhalis & $10(3.4)$ \\
\hline Morganella morganii & $24(4.5)$ & Enterococcus spp. & $10(3.4)$ \\
\hline Alcaligenes faecalis & $19(3.5)$ & Arthrobacter spp. & $8(2.7)$ \\
\hline Citrobacter spp. & $18(3.4)$ & Acinetobacter spp. & $6(2.0)$ \\
\hline Klebsiella spp. & $16(3.0)$ & Alcaligenes faecalis & $6(2.0)$ \\
\hline Arthrobacter spp. & $15(2.8)$ & Haemophilus influenzae & $5(1.7)$ \\
\hline Staphylococcus aureus & $14(2.6)$ & Corynebacterium spp. & $4(1.4)$ \\
\hline Other Streptococcus spp. & $12(2.2)$ & Fungi & $4(1.4)$ \\
\hline Fungi & $12(2.2)$ & Pantoea agglomerans & $4(1.4)$ \\
\hline Kerstersia gyiorum & $12(2.2)$ & Streptococcus pyogenes & $3(1.0)$ \\
\hline Escherichia coli & $11(2.0)$ & Enterobacter spp. & $3(1.0)$ \\
\hline Enterobacter spp. & $11(2.0)$ & Other $^{2}$ & $21(7.2)$ \\
\hline Pseudomonas spp. & $10(1.9)$ & No growth & $4(1.4)$ \\
\hline Achromobacter spp. & $7(1.3)$ & & \\
\hline Streptococcus pyogenes & $6(1.1)$ & & \\
\hline Other $^{1}$ & $38(7.1)$ & & \\
\hline No growth & $3(0.6)$ & & \\
\hline
\end{tabular}

Pathogens representing less than $1 \%$ of isolates in each group have been pooled as "Other". CoNS = coagulase-negative staphylococci

${ }^{1}$ Included pathogens listed from most to least prevalent: Stenotrophomonas maltophilia, Acinetobacter spp., Gemella morbillorum, Bordetella trematum, Globicatella sulfidifaciens, Aeromonas caviae, Escherichia hermannii, Streptococcus pneumoniae, Aerococcus viridans, Arcanobacterium haemolyticum, Dermabacter hominis, Kocuria spp., Microcuccus spp., Weeksella virosa, Raoultella ornithinolytica, Serratia marcescens, Lactococcus lactis, Weisella confusa, Neisseria meningitidis

${ }^{2}$ Included pathogens listed from most to least prevalent: Klebsiella spp., Aerococcus viridans, Lactococcus lactis, Leuconostoc spp., Macrococcus caseolyticus,

Moraxella nonliquefaciens, Raoultella ornithinolytica, Streptococcus spp., Citerobacter koseri, Morganella morganii, Serratia marcescens, Dietzia maris, Lactobacillus

salivarius, Shewanella putrefaciens, Stenotrophomonas maltophilia

\section{Most pathogenic bacteria in CSOM are susceptible to fluoroquinolones}

Susceptibility patterns for gram-negative and grampositive bacteria are presented in Table 4 and Table 5 , respectively. The majority of tested isolates were susceptible to quinolones (i.e., ciprofloxacin and norfloxacin), and resistance rates in bacteria relevant to CSOM ranged from 6.3 to $30.8 \%$ for $P$. aeruginosa and S. aureus, respectively. Several isolates within Enterobacteriaceae were resistant against aminoglycosides (range 6.9-25.8\%), slightly more increased resistance against gentamicin as compared to tobramycin. In contrast, resistance against aminoglycosides was lower for P. aeruginosa and higher in S. aureus. Almost half of isolated Enterobacteriaceae (42.6\%), and all $P$. aeruginosa, were resistant against chloramphenicol. A high resistance against trimethoprim-sulfamethoxazol was observed in Enterobacteriaceae while more than 90\% were susceptible to cefotaxime. We also found that a high proportion of S. aureus (53.8\%) were methicillin-resistant (MRSA). Furthermore, most pneumococci were resistant against benzylpenicillin (53.1\%) and trimethoprimsulfamethoxazol (78.1\%).

\section{Discussion}

It is a well known fact that infection of the middle ear in CSOM is usually polymicrobial, and the present study further confirms this as single isolates were identified in very few ear discharge samples [2]. In fact, a wide range of different species was identified. The high number of bacterial strains and degree of co-colonization reported, in both ear discharge and nasopharyngeal samples, can possibly be attributed to a higher specificity of MALDITOF MS as compared to conventional microbiological identification methods [15]. The slight difference in number of males and females in the current study is unclear, but may be due to differences in care-seeking 
Table 3 Pneumococccal serotypes identified in 34 isolates

\begin{tabular}{|c|c|c|}
\hline Serotype & $N$ & (\%) \\
\hline $19 \mathrm{~F}^{*}$ & 4 & (11.8) \\
\hline $6 A^{*}$ & 3 & (8.8) \\
\hline $17 \mathrm{~F}$ & 3 & (8.8) \\
\hline 16 & 2 & (5.9) \\
\hline 21 & 2 & (5.9) \\
\hline 38 & 2 & (5.9) \\
\hline $11 \mathrm{~A}$ & 2 & (5.9) \\
\hline $23 B$ & 2 & (5.9) \\
\hline NT & 2 & (5.9) \\
\hline $4^{*}$ & 1 & (2.9) \\
\hline $18 C^{*}$ & 1 & (2.9) \\
\hline $19 A^{*}$ & 1 & (2.9) \\
\hline $23 F^{*}$ & 1 & (2.9) \\
\hline $6 B^{*}$ & 1 & (2.9) \\
\hline $15 \mathrm{~A}$ & 1 & (2.9) \\
\hline $15 C$ & 1 & (2.9) \\
\hline $19 B$ & 1 & (2.9) \\
\hline 12 & 1 & (2.9) \\
\hline 13 & 1 & (2.9) \\
\hline 20 & 1 & (2.9) \\
\hline 34 & 1 & (2.9) \\
\hline Total & 34 & (100) \\
\hline Total PCV13-serotypes & 12 & (35.3) \\
\hline
\end{tabular}

Asterisks indicate serotypes included in the 13-valent pneumococcal conjugate vaccine (PCV13). NT = non-typeable

behaviour, as CSOM has been observed to affect gender equally [2]. However, a predominance of males was shown in an earlier report from the same clinic [18].

The nasopharyngeal microbiome has been proposed as a reservoir for pathogens involved in CSOM, and culture from this locus may grant important clinical information during the disease [19]. However, we found a low degree of correspondence between organisms present in the nasopharynx and middle ear discharge in the same patients. On the other hand, $>25 \%$ of the isolates from ear samples in patients with bilateral disease corresponded between the ears. It is possible that this is due to spread via the nasopharynx as the Eustachian tube is dysfunctional in CSOM, but may also be due to invasion from the outer ear canal by the same species in both ears [4]. The role of the nasopharyngeal flora in the pathogenesis and sustaining of CSOM is a field that needs to be further explored.

In accordance with our results, Taipale et al. [12] previously found Proteus and $P$. aeruginosa to be the most prevalent bacteria in 18 patients with CSOM in Luanda. In a Kenyan study, enterococci (28\%) were reported as a common pathogen in CSOM together with Proteus, $S$. aureus and $P$. aeruginosa, representing $32 \%, 12 \%$ and $11 \%$ of isolates, respectively [20]. Orji et al. [21] and Afolabi et al. [22] both found that $P$. aeruginosa is the dominating species in Nigeria followed by $S$. aureus and Klebsiella, respectively. On the other hand, Chirwa et al. [23] defined Proteus spp. as dominating followed by $P$. aeruginosa in Malawi. Thus, our results on the most prevalent pathogens in CSOM are in concordance with other recent studies from sub-Saharan Africa, although there seem to be geographical differences in the proportions between the species present.

An interesting finding was 19 isolates of Alcaligenes faecalis, which may be due to the occasional custom of filling the external meatus of the ear with bird droppings to prevent discharge, that we previously reported [24]. Furthermore, 12 isolates of Kerstersia gyiorum was detected. This gram-negative species belongs to the Alcaligenaceae family and has previously been found in CSOM with treatment failure due to antimicrobial resistance [25]. We did not have the possibility to study anaerobes in the present work due to methods used for sampling, transportation and microbiological diagnostics, although there is support for the presence of these bacteria in a majority of CSOM infections [6]. The high prevalence of CoNS and Corynebacterium spp., that both belong to the skin microbiome of the external auditory channel, was most likely contamination during collection [26]. It is possible that other isolated species also represent contamination from adjacent anatomical sites, and thus more studies are needed to elucidate the rich bacterial spectrum found in CSOM applying methods that enable specific species identification.

Aural toilet combined with empirical antibiotic therapy with topical quinolone antibiotics is the recommended first-hand treatment for uncomplicated CSOM although topical aminoglycosides, polymyxins or chloramphenicol are also used. Moreover, antiseptic topical agents such as aluminium acetate, acetic acid or boric acid may be effective and more feasible in resource-limited conditions due to their lower cost and availability [27-29]. The susceptibility patterns of the most frequently isolated species in this study suggest that quinolones or aminoglycosides may be more successful in clearing infection than colistin or chloramphenicol, the latter being the currently most used topical antibiotic for CSOM in Angola. Quinolones have previously been shown to be more effective than aminoglycosides, and would also be the preferred choice of the two drugs due to the potential ototoxicity of aminoglycosides [2]. However, resistance rates over $10 \%$ were observed for quinolones, which highlights the need to continuously determine antimicrobial susceptibility patterns. Other findings of interest regarding the general occurrence of antimicrobial resistance are high rates of 
Table 4 Susceptibility of gram-negative bacterial species to selected antimicrobial agents

\begin{tabular}{|c|c|c|c|c|c|c|c|c|c|c|c|}
\hline \multirow[t]{2}{*}{ Antimicrobial agent } & \multirow[t]{2}{*}{ Susceptibility $^{1}$} & \multicolumn{2}{|c|}{$\begin{array}{l}\text { Proteus spp. } \\
(N=89)^{2}\end{array}$} & \multicolumn{2}{|c|}{$\begin{array}{l}\text { non-Proteus } \\
\text { Enterobacteriaceae }(N=131)^{3}\end{array}$} & \multicolumn{2}{|c|}{$\begin{array}{l}\text { P. aeruginosa } \\
(N=63)^{4}\end{array}$} & \multicolumn{2}{|c|}{$\begin{array}{l}\text { H. influenzae } \\
(N=5)\end{array}$} & \multicolumn{2}{|c|}{$\begin{array}{l}\text { M. catarrhalis } \\
(N=9)\end{array}$} \\
\hline & & $N$ & (\%) & $N$ & (\%) & $N$ & (\%) & $N$ & (\%) & $N$ & (\%) \\
\hline \multirow[t]{2}{*}{ Amoxicillin } & $S$ & & & & & & & 4 & (80) & & \\
\hline & $\mathrm{R}$ & & & & & & & 1 & (20) & & \\
\hline \multirow[t]{3}{*}{ Piperacillin-tazobactam } & S & 88 & (98.9) & 125 & $(95.4)$ & 61 & $(96.8)$ & & & & \\
\hline & । & & & 5 & (3.8) & & & & & & \\
\hline & $\mathrm{R}$ & 1 & $(1.1)$ & 1 & $(0.8)$ & 2 & $(3.2)$ & & & & \\
\hline \multirow[t]{3}{*}{ Cefotaxime } & S & 88 & (98.9) & 121 & $(92.3)$ & & & 5 & (100) & 9 & $(100)$ \\
\hline & । & & & 1 & $(0.8)$ & & & & & & \\
\hline & $\mathrm{R}$ & 1 & $(1.1)$ & 9 & $(6.9)$ & & & & & & \\
\hline \multirow[t]{3}{*}{ Ceftazidime } & S & 88 & $(1.1)$ & 122 & $(93.1)$ & 62 & $(98.4)$ & & & & \\
\hline & I & & & 2 & $(1.5)$ & & & & & & \\
\hline & $\mathrm{R}$ & 1 & $(1.1)$ & 7 & (5.3) & 1 & (1.6) & & & & \\
\hline \multirow[t]{2}{*}{ Imipenem } & S & 89 & $(100)$ & 122 & $(93.1)$ & 60 & $(95.2)$ & & & & \\
\hline & । & & & 9 & $(6.9)$ & 3 & $(4.8)$ & & & & \\
\hline \multirow[t]{2}{*}{ Meropenem } & S & 89 & $(100)$ & 131 & $(100)$ & 52 & $(82.5)$ & 5 & $(100)$ & 9 & (100) \\
\hline & I & & & & & 11 & $(17.5)$ & & & & \\
\hline \multirow[t]{3}{*}{ Ciprofloxacin } & S & 76 & (85.4) & 105 & $(80.2)$ & 58 & $(92.1)$ & 5 & (100) & 9 & (100) \\
\hline & I & 3 & (3.4) & 7 & (5.3) & 1 & (1.6) & & & & \\
\hline & $\mathrm{R}$ & 10 & $(11.2)$ & 19 & $(14.5)$ & 4 & (6.3) & & & & \\
\hline \multirow[t]{3}{*}{ Gentamicin } & $S$ & 63 & (70.8) & 106 & (80.9) & 58 & $(92.1)$ & & & & \\
\hline & I & 3 & (3.4) & 3 & $(2.3)$ & 1 & (1.6) & & & & \\
\hline & $\mathrm{R}$ & 23 & (25.8) & 22 & $(16.8)$ & 4 & (6.3) & & & & \\
\hline \multirow[t]{3}{*}{ Tobramycin } & S & 72 & (80.9) & 109 & $(83.2)$ & 59 & $(93.7)$ & & & & \\
\hline & I & 5 & (5.6) & 13 & (9.9) & & & & & & \\
\hline & $\mathrm{R}$ & 12 & (13.5) & 9 & (6.9) & 4 & (6.3) & & & & \\
\hline \multirow[t]{2}{*}{ Tetracycline } & S & & & & & & & 4 & (80) & 7 & $(77.8)$ \\
\hline & $\mathrm{R}$ & & & & & & & 1 & (20) & 2 & $(22.2)$ \\
\hline \multirow[t]{3}{*}{ Trimethoprim-sulfamethoxazole } & $S$ & 31 & $(34.8)$ & 71 & $(54.2)$ & & & 2 & (40) & 1 & $(11.1)$ \\
\hline & । & 2 & $(2.2)$ & 2 & $(1.5)$ & & & & & 1 & $(11.1)$ \\
\hline & $\mathrm{R}$ & 56 & $(62.9)$ & 58 & $(44.3)$ & & & 3 & (60) & 7 & $(77.8)$ \\
\hline \multirow[t]{2}{*}{ Chloramphenicol } & S & & & 27 & $(57.4)$ & & & & & & \\
\hline & $\mathrm{R}$ & & & 20 & $(42.6)$ & 42 & $(100)$ & & & & \\
\hline \multirow[t]{2}{*}{ Colistin } & S & & & $26^{3}$ & $(55.3)$ & $40^{4}$ & $(95.2)$ & & & & \\
\hline & $\mathrm{R}$ & $70^{2}$ & $(100)$ & $21^{3,5}$ & $(44.7)$ & $2^{4,6}$ & $(4.8)$ & & & & \\
\hline
\end{tabular}

Isolates grouped as non-Proteus Enterobacteriaceae were 38 Providencia spp., 25 Morganella morganii, 18 Klebsiella spp., 18 Citrobacter spp., 13 Enterobacter spp., 13 Escherichia spp., 3 Pantoea agglomerans, 2 Serratia marcescens and 1 Raoultella ornithinolytica

${ }^{1} \mathrm{~S}$, susceptible; I, intermediate; $\mathrm{R}$, resistant

${ }^{2}$ Susceptibility testing for Proteus spp. against colistin was done with 70 randomly selected isolates

${ }^{3}$ Susceptibility testing for non-Proteus Enterobacteriaceae against chloramphenicol and colistin was done with 47 randomly selected isolates

${ }^{4}$ Susceptibility testing for $P$. aeruginosa against chloramphenicol and colistin was done with 42 randomly selected isolates

${ }^{5}$ All MIC $\geq 64 \mathrm{mg} / \mathrm{L}$ including Providencia, Morganella, Enterobacter and Serratia spp.

${ }^{6}$ All MIC $=4 \mathrm{mg} / \mathrm{L}$

MRSA, aminoglycoside-resistance among gram-negatives and penicillin non-susceptible pneumococci. On the other hand, only a small number of Enterobacteriaceae were resistant to cefotaxime, i.e. probable carriage of extended- spectrum beta-lactamases, and carbapenems which has previously been reported as common in Luanda [14].

Considering the risk for antimicrobial resistance to all topical antibiotics tested, and the fact that these 
Table 5 Susceptibility of gram-positive bacterial species to selected antimicrobial agents

\begin{tabular}{|c|c|c|c|c|c|c|c|}
\hline \multirow[t]{3}{*}{ Antimicrobial agent } & \multirow[t]{3}{*}{ Susceptibility $^{1}$} & \multirow{2}{*}{\multicolumn{2}{|c|}{$\frac{\text { S. pneumoniae }}{(N=32)}$}} & \multirow{2}{*}{\multicolumn{2}{|c|}{$\frac{\text { S. pyogenes }}{(N=9)}$}} & \multirow{2}{*}{\multicolumn{2}{|c|}{$\frac{\text { S. aureus }}{(N=13)}$}} \\
\hline & & & & & & & \\
\hline & & N & (\%) & $N$ & $(\%)$ & N & $(\%)$ \\
\hline \multirow[t]{2}{*}{ Benzylpenicillin } & S & 15 & $(46.9)$ & 9 & (100) & & \\
\hline & $R$ & 17 & (53.1) & & & & \\
\hline \multirow[t]{2}{*}{ Cefoxitin $^{2}$} & S & & & & & 6 & $(46.2)$ \\
\hline & $\mathrm{R}$ & & & & & 7 & (53.8) \\
\hline \multirow[t]{2}{*}{ Norfloxacin ${ }^{3}$} & S & 32 & $(100)$ & & & 9 & $(69.2)$ \\
\hline & $\mathrm{R}$ & & & & & 4 & (30.8) \\
\hline \multirow[t]{2}{*}{ Tobramycin } & S & & & & & 4 & (30.8) \\
\hline & $\mathrm{R}$ & & & & & 9 & $(69.2)$ \\
\hline \multirow[t]{2}{*}{ Erythromycin } & S & 32 & (100) & 9 & $(100)$ & 12 & (92.3) \\
\hline & $\mathrm{R}$ & & & & & 1 & $(7.7)$ \\
\hline \multirow[t]{3}{*}{ Clindamycin } & S & 32 & $(100)$ & 9 & (100) & 11 & (84.6) \\
\hline & I & & & & & 1 & $(7.7)$ \\
\hline & $\mathrm{R}$ & & & & & 1 & $(7.7)$ \\
\hline \multirow[t]{3}{*}{ Tetracycline } & S & 24 & (75) & 3 & (33.3) & & \\
\hline & 1 & 1 & (3.1) & & & & \\
\hline & $\mathrm{R}$ & 7 & $(21.9)$ & 6 & $(66.7)$ & & \\
\hline Fusidic acid & S & & & & & 13 & $(100)$ \\
\hline \multirow[t]{2}{*}{ Rifampicin } & S & 27 & (84.4) & & & & \\
\hline & R & 5 & $(15.6)$ & & & & \\
\hline \multirow[t]{3}{*}{ Trimethoprim-sulfamethoxazole } & S & 6 & (18.8) & & & 13 & $(100)$ \\
\hline & 1 & 1 & (3.1) & & & & \\
\hline & $\mathrm{R}$ & 25 & $(78.1)$ & & & & \\
\hline
\end{tabular}

${ }^{1} \mathrm{~S}$, susceptible; $\mathrm{I}$, intermediate; $\mathrm{R}$, resistant

2 Screening substance for methicillin resistance

${ }^{3}$ Screening substance for quinolone resistance

antibiotics may not be readily available in resourcelimited settings, the use of topical antiseptics should be explored. Treatment with one-off application of boric acid powder has been reported to be as effective as topical ciprofloxacin while treatment with aluminium acetate has showed similar results compared to topical aminoglycosides [2, 29]. In a randomized controlled trial in Tanzania the treatment choice for CSOM in children was daily aural toilet and topical boric acid in alcohol solution [30]. Furthermore, Youn et al. [31] showed a high bactericidal effect of aluminium acetate and acetic acid against MRSA and quinolone-resistant $P$. aeruginosa.

Within the framework of the current project at HJM, a film has been produced informing about the condition to improve care of CSOM. Here ear care by "dry mopping" and protecting the ear from contamination is described in detail. It is available online and is planned to be presented in social media and television in Angola [32]. Such information and improved treatment in health care centers and hospitals might reduce the burden of CSOM and its complications.

As CSOM is generally preceded by an episode of AOM, which is predominantly caused by pneumococci, non-typeable Haemophilus influenzae or Moraxella catarrhalis [33], an important aspect of CSOM prevention is the reduction of AOM. In fact, incidence rates of AOM in western sub-Saharan Africa has been estimated to be over $40 \%$, with a majority of cases occurring in children under 5 years of age [3]. Some studies suggest that the use of PCV may have a positive effect on the all-cause AOM incidence, which may lead to a subsequently reduced CSOM incidence [34, 35]. PCV13 was introduced in Angola in 2013 and WHO estimates that the proportion of newborns who received three vaccine doses has risen from 9\% in 2013 to 58\% in 2015 and 2016 [36]. Although a small number of pneumococci were isolated, our results show that vaccine serotypes are present in Angola indicating that any obvious serotype replacement, which is a well-documented effect of 
PCV in many areas of the world, has not occurred, at least not in the mixed age group studied [37, 38]. Considering these numbers and the possible effects on otitis media, a higher degree of vaccine coverage is desirable in Angola. However, further studies are required on this topic.

\section{Conclusions}

The results of the current study largely agree with other studies concerning the dominating pathogens found in CSOM although a greater number of individual species were identified. Proteus spp., $P$. aeruginosa and enterococci were the most frequently identified bacteria in ear discharge. Based on the susceptibility testing performed the best choices for topical antibiotic treatment of CSOM in the current outpatients setting would be quinolones. However, considering the risk for unsuccessful treatment due to antimicrobial resistance, topical antiseptic agents should be considered as the first-hand choice for treatment of CSOM in Angola.

\section{Additional files}

Additional file 1: Multilingual abstracts in the six official working languages of the United Nations. (PDF 675 kb)

Additional file 2: Primer list and PCR cycling conditions. (PDF $126 \mathrm{~kb}$ )

Additional file 3: Full patient list. (PDF 258 kb)

\section{Abbreviations}

AOM: Acute otitis media; CoNS: Coagulase-negative staphylococci; CSOM: Chronic suppurative otitis media; ENT: Ear, nose and throat; HJM: Hospital Josina Machel; MALDI-TOF MS: Matrix-assisted laser desorption/ionization - time of flight mass spectrometry; mPCR: Multiplex polymerase chain reaction; MRSA: Methicillin-resistant S. aureus; PCV: Pneumococcal conjugate vaccine; WHO: World Health Organization

\section{Funding}

This work was supported by grants from Foundations of Anna and Edwin Berger (K.R.) and Gyllenstierna-Krapperup (K.R. and A.R.), as well as the Swedish Medical Research Council (grant number K2015-57X-0316343-4, www.vr.se), and Skåne County Council's research and development foundation (K.R.). Moreover, support was obtained from Päivikki and Sakari Sohlberg Foundation (T.P.), and the Paediatric Research Foundation (both in Helsinki, Finland) (T.P.).

\section{Availability of data and materials}

The datasets used and/or analysed during the current study are available from the corresponding author on reasonable request.

\section{Authors' contributions}

MF initiated the study, collected samples and epidemiological data. KR, MF $\AA ̊ R$ and TP designed the study and wrote the manuscript together with FU. EM did susceptibility testing and wrote the manuscript. MP and FU typed bacteria and did susceptibility testing. JT and SH contributed to the microbiological diagnostics. All authors read and approved the final manuscript.

\section{Ethics approval and consent to participate}

Authorization for the study was obtained from the Ethical committee at the Medical National Council of Angola, Scientific Council of the Faculty of Medicine of Agostinho Neto University and the General Director of Hospital
Josina Machel. Before enrollment, the patients or their guardians gave informed consent.

\section{Competing interests}

The authors declare that they have no competing interests.

\section{Author details}

${ }^{1}$ Clinical Microbiology, Department of Translational Medicine, Faculty of Medicine, Lund University, Malmö, Sweden. ${ }^{2} \mathrm{ORL}$-department Hospital Josina Machel, Faculty of Medicine, Agostinho Neto University, Luanda, Angola. ${ }^{3}$ Näshälsan Höllviken AB, Höllviken, Sweden. ${ }^{4}$ EUCAST Development Laboratory, c/o Clinical Microbiology, Central Hospital, Växjö, Sweden. ${ }^{5}$ Department of Molecular Genetics and Infection Biology, University of Greifswald, Greifswald, Germany. ${ }^{6}$ Children's Hospital, Helsinki University Hospital, Helsinki, Finland and University of Helsinki, Helsinki, Finland.

Received: 9 October 2017 Accepted: 10 April 2018

Published online: 03 May 2018

\section{References}

1. Acuin J. Chronic suppurative otitis media : burden of illness and management options. Geneve: World Health Organization; 2004.

2. Mittal R, Lisi CV, Gerring R, Mittal J, Mathee K, Narasimhan G, et al. Current concepts in the pathogenesis and treatment of chronic suppurative otitis media. J Med Microbiol. 2015;64(10):1103-16.

3. Monasta L, Ronfani L, Marchetti F, Montico M, Vecchi Brumatti L, Bavcar A, et al. Burden of disease caused by otitis media: systematic review and global estimates. PLoS One. 2012;7(4):e36226.

4. Verhoeff M, van der Veen EL, Rovers MM, Sanders EA, Schilder AG. Chronic suppurative otitis media: a review. Int J Pediatr Otorhinolaryngol. 2006;70(1):1-12.

5. Jensen RG, Johansen HK, Bjarnsholt T, Eickhardt-Sorensen SR, Homoe P. Recurrent otorrhea in chronic suppurative otitis media: is biofilm the missing link? Eur Arch Otorhinolaryngol. 2017;274(7):2741-7.

6. Brook $I$. The role of anaerobic bacteria in chronic suppurative otitis media in children: implications for medical therapy. Anaerobe. 2008;14(6):297-300.

7. Hand JM, Pankey GA. Tuberculous Otomastoiditis. Microbiol Spectr. 2016; 4(6) https://doi.org/10.1128/microbiolspec.TNMI7-0020-2016.

8. Angola Data Portal. African development bank group, Abidjan. 2014. http:// angola.opendataforafrica.org. Accessed 29 Aug 2017.

9. UNICEF Data Angola page. UNICEF, Geneva. https://data.unicef.org/country/ ago. 2013-2015. Accessed 14 Sept 2017.

10. Bastos I, Reimer $\AA$, Lundgren K. Chronic otitis media and hearing loss in urban schoolchildren in Angola - a prevalence study. Int J Pediatr Otorhinolaryngol. 1993;2:129-40.

11. Taipale A, Pelkonen T, Taipale M, Roine I, Bernardino L, Peltola H, et al. Otorhinolaryngological findings and hearing in HIV-positive and HIVnegative children in a developing country. Eur Arch Otorhinolaryngol. 2011; 268(10):1527-32.

12. Taipale A, Pelkonen T, Taipale M, Bernardino L, Peltola H, Pitkaranta A. Chronic suppurative otitis media in children of Luanda, Angola. Acta Paediatr. 2011;100(8):e84-8.

13. Conceicao T, Coelho C, Santos Silva I, de Lencastre H, Aires-de-Sousa M. Methicillin-resistant Staphylococcus aureus in the community in Luanda, Angola: blurred boundaries with the hospital setting. Microb Drug Resist. 2016;22(1):22-7.

14. Kieffer N, Nordmann P, Aires-de-Sousa M, Poirel L. High prevalence of carbapenemase-producing Enterobacteriaceae among hospitalized children in Luanda, Angola. Antimicrob Agents Chemother. 2016;60(10):6189-92.

15. Papp Z, Elgabsi H, Toth L. MALDI-TOF mass spectrometry reveals a highly complex bacterial profile of otitis media with effusion. Int J Pediatr Otorhinolaryngol. 2016;86:189-92.

16. da Gloria Carvalho M, Pimenta FC, Jackson D, Roundtree A, Ahmad Y, Millar $E V$, et al. Revisiting pneumococcal carriage by use of broth enrichment and PCR techniques for enhanced detection of carriage and serotypes. J Clin Microbiol. 2010;48(5):1611-8.

17. The European Committee on Antimicrobial Susceptibility Testing. Breakpoint tables for interpretation of MICs and zone diameters Version 7.1. 2017. http://www.eucast.org/clinical_breakpoints/. Accessed 2017. 
18. Bastos I, Janzon L, Lundgren $K$, Reimer A. Otitis media and hearing loss in children attending an ENT clinic in Luanda, Angola. Int J Pediatr Otorhinolaryngol. 1990;20(2):137-48.

19. Chang J, Lee S-H, Choi J, Im GJ, Jung HH. Nasopharynx as a microbiologic reservoir in chronic suppurative otitis media: preliminary study. Clin Exp Otorhinolaryngol. 2011:4(3):122-5.

20. Aduda DS, Macharia IM, Mugwe P, Oburra H, Farragher B, Brabin B, et al. Bacteriology of chronic suppurative otitis media (CSOM) in children in Garissa district, Kenya: a point prevalence study. Int J Pediatr Otorhinolaryngol. 2013;77(7):1107-11.

21. Orji FT, Dike BO. Observations on the current bacteriological profile of chronic suppurative otitis media in south eastern Nigeria. Ann Med Health Sci Res. 2015;5(2):124-8.

22. Afolabi OA, Salaudeen AG, Ologe FE, Nwabuisi C, Nwawolo CC. Pattern of bacterial isolates in the middle ear discharge of patients with chronic suppurative otitis media in a tertiary hospital in north Central Nigeria. Afr Health Sci. 2012;12(3):362-7.

23. Chirwa M, Mulwafu W, Aswani JM, Masinde PW, Mkakosya R, Soko D. Microbiology of chronic suppurative otitis media at queen Elizabeth central hospital, Blantyre, Malawi: a cross-sectional descriptive study. Malawi Med J. 2015;27(4):120-4.

24. Filipe M, Reimer A, Matuschek E, Paul M, Pelkonen T, Riesbeck K Fluoroquinolone-resistant Alcaligenes faecalis related to chronic suppurative otitis media, Angola. Emerg Infect Dis. 2017;23(10):1740-2.

25. Uysal EB, Celik C, Tuzcu N, Can F, Dogan M, Erturk R, et al. a case of chronic suppurative otitis media caused by Kerstersia gyiorum. APMIS. 2015;123(11):986-9.

26. Stenfors $L E$, Raisanen $S$. Quantity of aerobic bacteria in the bony portion of the external auditory canal of children. Int J Pediatr Otorhinolaryngol. 2002; 66(2):167-73.

27. Macfadyen CA, Acuin JM, Gamble C. Topical antibiotics without steroids for chronically discharging ears with underlying eardrum perforations. Cochrane Database Syst Rev. 2005;(4):Cd004618.

28. Daniel SJ. Topical treatment of chronic suppurative otitis media. Curr Infect Dis Rep. 2012;14(2):121-7.

29. Loock JW. A Randomised controlled trial of active chronic otitis media comparing courses of eardrops versus one-off topical treatments suitable for primary, secondary and tertiary healthcare settings. Clin Otolaryngology. 2012:37(4):261-70

30. Minja BM, Moshi NH, Ingvarsson L, Bastos I, Grenner J. Chronic suppurative otitis media in Tanzanian school children and its effects on hearing. East Afr Med J. 2006;83(6):322-5.

31. Youn $\mathrm{CH}$, Jang S-J, Jo E-R, Choi JA, Sim J-H, Cho SI. Comparative antibacterial activity of topical antiseptic eardrops against methicillinresistant Staphylococcus aureus and quinolone-resistant Pseudomonas aeruginosa. Int J Pediatr Otorhinolaryngol. 2016;85:80-3.

32. Filipe M, Reimer $\AA$, Kuatoko P, da Cruz A. Como tratar otorréia [Video]. 2017. https://www.youtube.com/watch?v=T8yH41XmfZw. Accessed Sept 2017.

33. Rovers MM, Schilder AG, Zielhuis GA, Rosenfeld RM. Otitis media. Lancet. 2004;363(9407):465-73.

34. Gisselsson-Solen M. Trends in otitis media incidence after conjugate pneumococcal vaccination; a national observational study. Pediatr Infect Dis J. 2017;36(11):1027-31.

35. Sartori AL, Minamisava R, Bierrenbach AL, Toscano CM, Afonso ET, MoraisNeto OL, et al. Reduction in all-cause otitis media-related outpatient visits in children after PCV10 introduction in Brazil. PLoS One. 2017;12(6):e0179222.

36. WHO vaccine-preventable diseases: Monitoring system. 2017 global summary. 2017. World Health Organization, Geneva. http://apps.who.int/ immunization_monitoring/globalsummary. Accessed 4 Oct 2017.

37. Devine VT, Cleary DW, Jefferies JM, Anderson R, Morris DE, Tuck AC, et al. The rise and fall of pneumococcal serotypes carried in the PCV era. Vaccine. 2017;35(9):1293-8.

38. Flasche S, Givon-Lavi N, Dagan R. Using pneumococcal carriage data to monitor postvaccination changes in the incidence of pneumococcal otitis media. Am J Epidemiol. 2016;184(9):652-9.

39. Golbez. Map of the provinces of Angola, named with ISO standard names. 2005. https://commons.wikimedia.org/wiki/File:Angola_provinces_named. png. Accessed Sept 2017.

40. TUBS. Angola in Africa. 2011. https://commons.wikimedia.org/wiki/File: Angola_in_Africa.svg. Accessed t 2017.

\section{Ready to submit your research? Choose BMC and benefit from:}

- fast, convenient online submission

- thorough peer review by experienced researchers in your field

- rapid publication on acceptance

- support for research data, including large and complex data types

- gold Open Access which fosters wider collaboration and increased citations

- maximum visibility for your research: over $100 \mathrm{M}$ website views per year

At BMC, research is always in progress.

Learn more biomedcentral.com/submissions 